\title{
THE BOND STRENGTH OF A CALCIUM SULFOALUMINATE CEMENT-BASED REPAIR MORTAR
}

\author{
XUMIN LI, CHUANMIN XU, "PENG DU \\ Shandong Provincial Key Laboratory of Preparation and Measurement of Building Materials, \\ University of Jinan, Jinan, China \\ "E-mail: mse_dup@163.com
}

Submitted August 13, 2019; accepted September 30, 2019

\begin{abstract}
Keywords: Calcium sulfoaluminate cement, Bond strength, Interface roughness, Moisture, Polycarboxylate superplasticiser
This study investigated the interfacial bond strength between a calcium sulfoaluminate cement (CSA) mortar as a repair material and an old substrate. The surface of the old substrate was treated to have a different roughness (smooth, slightly rough and seriously rough) and moisture. In addition, the effect of a polycarboxylate superplasticiser on the bond properties of the CSA mortar was also studied. The results show that the interface between the CSA mortar and the old substrate is a weak area, and all the test specimens break at the interface. As the interface roughness increases, the bond strength at 4h increases from 1.0 MPa to $3.1 \mathrm{MPa}$, indicating that the higher interface roughness is beneficial in improving the bond strength. The wet interface has a lower bond strength than the dry interface. Adding an appropriate amount of polycarboxylate superplasticiser is beneficial to improving the bond strength of the mortar. When the polycarboxylate superplasticiser dosage is $0.9 \%$, the bond strength is the highest.
\end{abstract}

\section{INTRODUCTION}

Concrete is one of the most widely used structural materials in the world, due to its characteristics of high strength, longevity and good stability. Nowadays, cement concrete has been widely used in pavements and airport runaways [1]. However, concrete pavements have premature deterioration or damage due to the combined effects of environmental and mechanical loadings. Therefore, the rapid repair of the deteriorated pavement is essential to eliminate the traffic congestion, traffic accidents, and environmental pollution caused by the poor road conditions. In recent years, people have developed many materials for concrete pavement repair, which can be divided into three categories: cement-based materials, polymer-modified cement-based materials, and polymer or resin materials [2-5]. In this study, a sulfoaluminate cement mortar was used as a repair material, due to its characteristics of rapid hardening, high early strength, high corrosion resistance, high impermeability and low dry shrinkage. There is also its good compatibility between a CSA mortar and an old substrate.

As we all know, the effectiveness of a repair is related to the bond properties between the repair material and the old substrate [6]. Many factors including interface the roughness [7-10], the adhesive agents [11-14], the mechanical properties of the two cementitious materials and the evaluation method of the bond strength [15-17] can influence the bond strength. These factors must be considered in order to increase the bond property. Among these factors, the interface roughness is an im- portant factor affecting the mechanical behaviour of the interface, which affects the bond strength by affecting the cohesion of the interface [18-19].

In addition, one parameter that is recognised to affect the bond performance between two cementitious materials is the availability of moisture at the old substrate surface before the casting of the new material [20]. The current research on the moisture that influences the bond strength requires that the old substrate is pre-wetted to a saturated surface dry (SSD) condition before the repair material can be applied. It has been reported that when casting a fresh material over a dry substrate, the substrate may absorb part of the mixing water from the former, thus, forcing the water to migrate from the new material to the substrate [21]. The water migration would lead to an internal stress at the interface, thus, making it a weak area. It is, therefore, believed that by providing extra moisture at the interface before the casting of the new material, it can reduce the water migration, so it is possible to improve bond strength. However, the extra water on the surface of the old substrate has the potential to increase the water to cement ratio (w/c ratio) of the overlay mortar and, hence, lower the strength of the thin layer of the mortar just above the interface [20]. Although a pre-wetted old substrate surface has been incorporated into concrete repair practice, little research has been supported that the substrates pre-wetted to an SSD state can be advantageous for a better bond [22-23]. On the contrary, the research undertaken by Silfwerbrabd [24] and Beushausen [25] suggests that pre-wetting the surface to an SSD state has no beneficial impact on the bond strength. 
In this study, we used an ordinary Portland cement (OPC) mortar block as the old substrate and a CSA mortar as the repair material. The effect of the different roughness and moisture of the old substrate surface on the bond properties were studied to find an optimal interface treatment method. Moreover, the effect of adding a polycarboxylate superplasticiser on the bond properties of the CSA mortar was also studied.

\section{EXPERIMENTAL}

Materials

We used the OPC and the CSA cement to prepare the old substrate and the repair mortar. The PO 32.5 Portland cement and 42.5R CSA are from Shandong Shanshui Cement Group Limited (Sunny), China. The particle size distribution of the OPC and CSA by laser granulometry are given in Figure 1. The polycarboxylate superplasticiser is a solid powder.

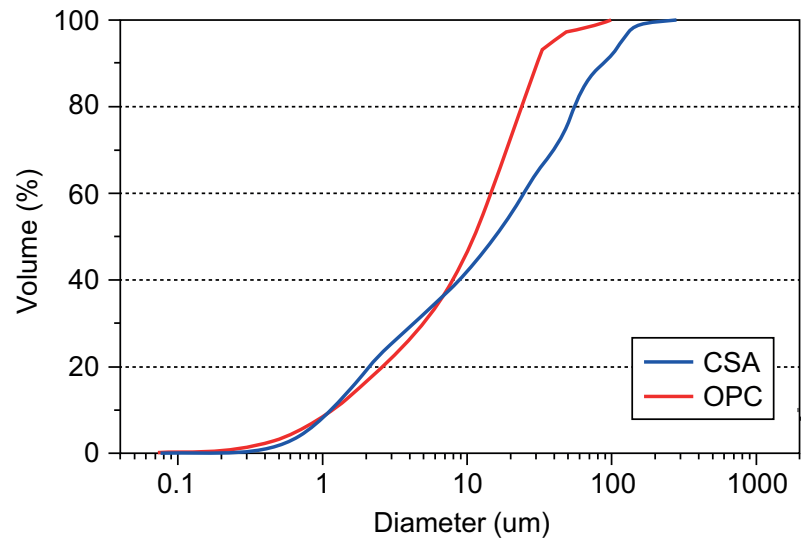

Figure 1. The particle size distribution of the OPC and CSA.

\section{Interface preparation of the old substrate}

The bond strength was tested referring to JC/T23812016 Repairing mortar. Three extruded polystyrene foam blocks of $40 \times 40 \times 80 \mathrm{~mm}$ were fabricated, and the foam block was placed into a $40 \times 40 \times 160 \mathrm{~mm}$ mould to fill one side, and then the other side was cast with the OPC mortar (cement: standard sand: water $=1: 3: 0.5$ ). It was cured for more than 28 days under the standard curing conditions as the old substrate. Subsequently, to study the effect of the interface roughness on the bond properties, the combined specimens were divided into three groups according to the different substrate surface treatment (Figure 2):

- a smooth surface (S1);

- a slightly rough surface, which is a one-way scratch with a scratch depth of about $1 \mathrm{~mm}$;

- a seriously rough surface, which is a two-way scratch with a scratch depth of about $1 \mathrm{~mm}$. These substrate surfaces are dry.

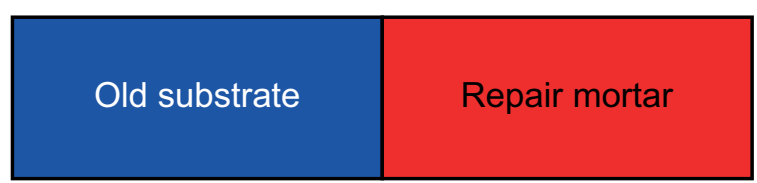

Figure 3. The specimen used for the bond strength.

The seriously rough interface was used to study the effect of the interface moisture on the bond properties. The treated specimen was rinsed underwater for $10 \mathrm{~min}$, and the substrate surface moisture was dried with paper to perform a bond strength test (S4).

\section{Bond strength test}

We placed the old substrate into a $40 \times 40 \times 160 \mathrm{~mm}$ mould to fill one side, and cast the CSA mortar on the other side to make the combined specimen of the old substrate and the repair mortar (as shown in Figure 3). Subsequently, it was demoulded and stored until testing under the standard curing conditions. The flexural bond strength of the specimens was tested at the age of 4 hours, 1 day and 3 days.

Preparation of the specimen with the polycarboxylate superplasticiser

The polycarboxylate superplasticiser dosage of the repair mortar was 0 wt. $\%, 0.1$ wt. $\%, 0.3$ wt. $\%, 0.5$ wt. $\%$, 0.7 wt. $\%, 0.9$ wt. $\%$, and 1.1 wt. $\%$, respectively. The surface of the old substrate was smooth and dry. The specimens were prepared according to the method of Section 2.2 to test the bond strength.
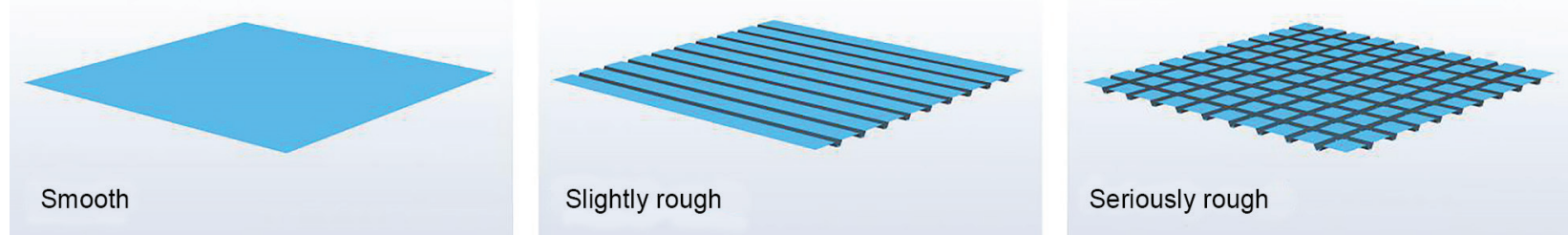

Figure 2. The interface roughness treatment. 


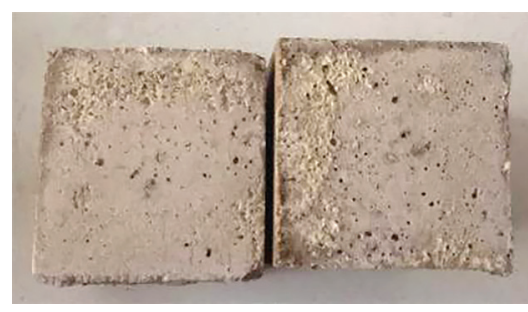

a)

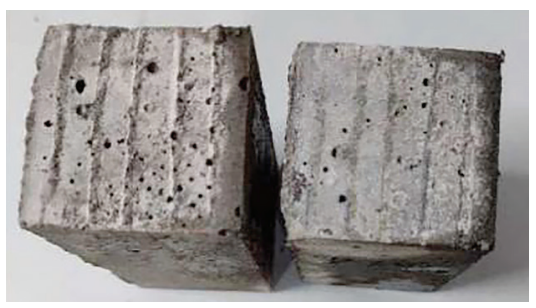

b)

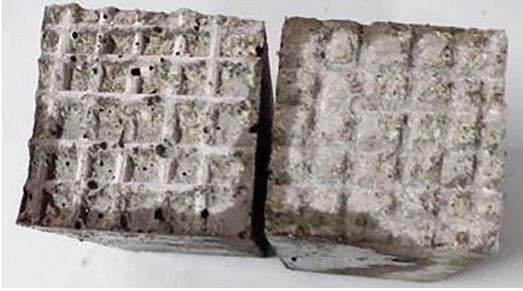

c)

Figure 4. The fracture interface after the bond strength test at $4 \mathrm{~h}$ (two pictures for each surface, the left picture is the CSA mortar surface and the right one is the old substrate surface).

\section{RESULTS AND DISCUSSIONS}

The effect of the interface roughness on the bond strength

All the test specimens broke at the interface when performing the flexural bond strength test, which indicated that the interface is a weak area (Figure 4). The bond strength of the different interface roughness is shown in Figure 5. The results indicated that the bond strength of the combined specimens increased with an increase in the interface roughness. The $\mathrm{S} 3$ specimen has a high bond strength at $4 \mathrm{~h}$ of about 3.1 MPa. And this is higher than the bond strength of S1 at $4 \mathrm{~h}$. This shows that the interface roughness affects the bond strength significantly. The enhancement of the bond strength of the serious interface roughness specimens is because of the increase in the available bond contact area, which

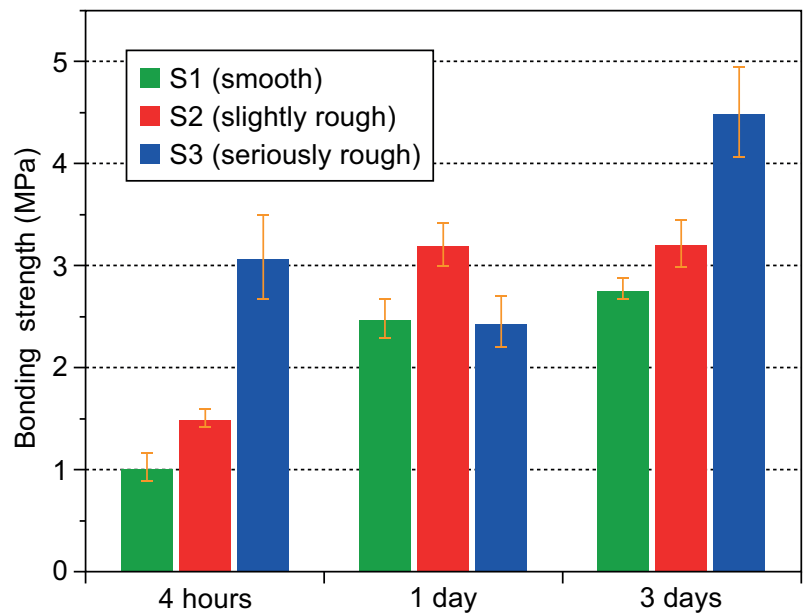

Figure 5 . The bond strength of the specimens with the different interface roughness.

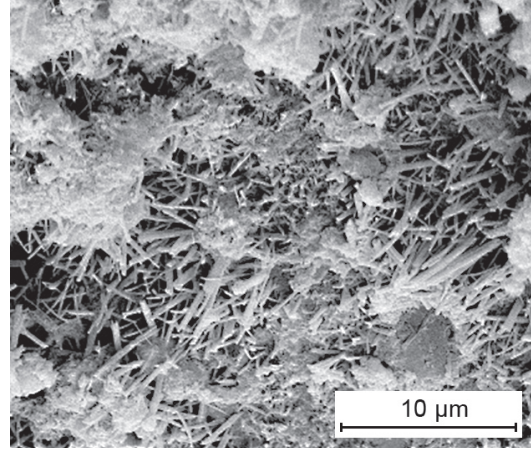

a)

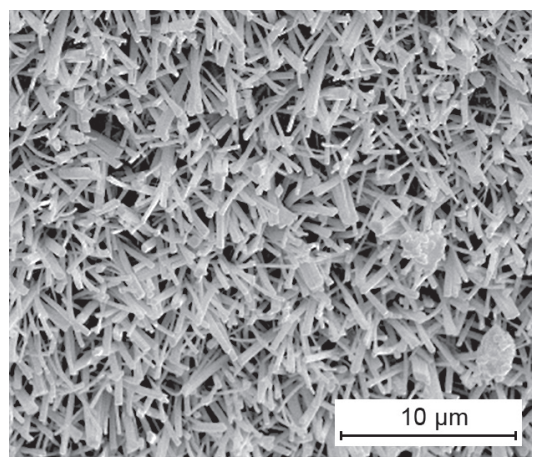

d)

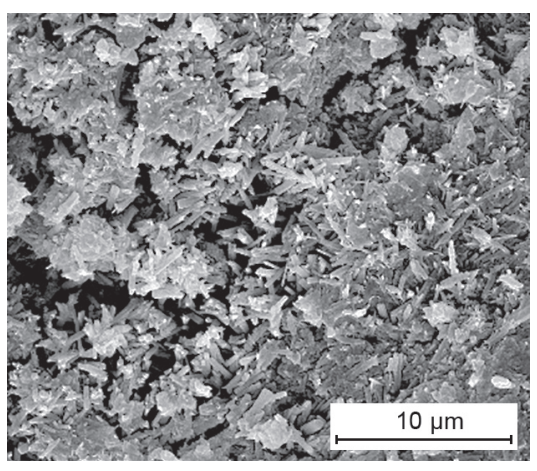

b)

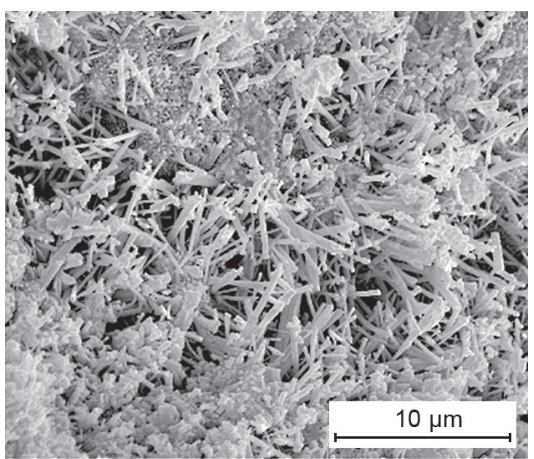

e)

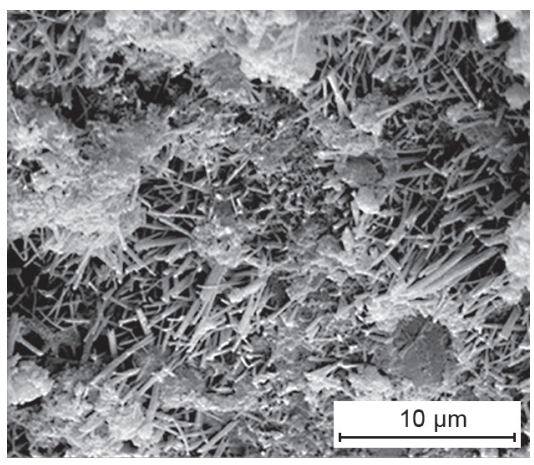

c)

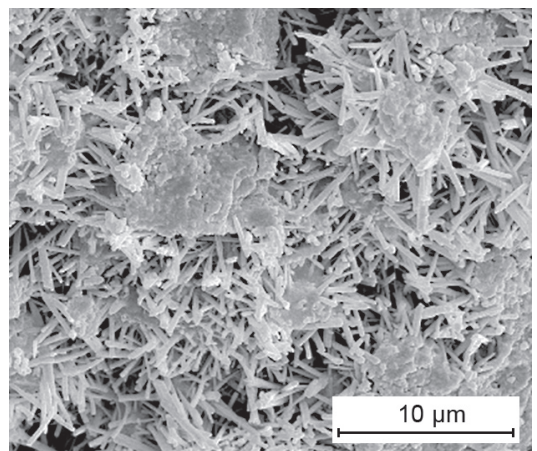

f)

Figure 6. The SEM image of specimens: a) - c) are the SEM images of S1, S2, and S3 hydration for 4 hours, respectively, and d) are the SEM images of S1, S2, and S3 hydration for 3 days, respectively. 
can absorb more cement mortar. Besides, the mechanical interlocking between the old substrate and the repair material was improved as the interface roughness increased, and improved the interfacial bond performance.

As can be seen from Figure 6, S1, S2, and S3 formed a large amount of ettringite at $4 \mathrm{~h}$. And S1 and S2 was distributed with more ettringite crystals. Due to the faster growth rate of these crystals, the formed network structure is not dense, resulting in a decrease in the bond strength. On the contrary, S3 contains more gels, which makes the hydration product distribution more uniform, reduces the porosity and improves the bond strength. The bond strength increased with an increase in the gel content with the extension of the hydration age.

To research the effect of the surface roughness on the hydration products of the CSA mortar, the XRD patterns of S1, S2 and S3 are shown in Figure 7.

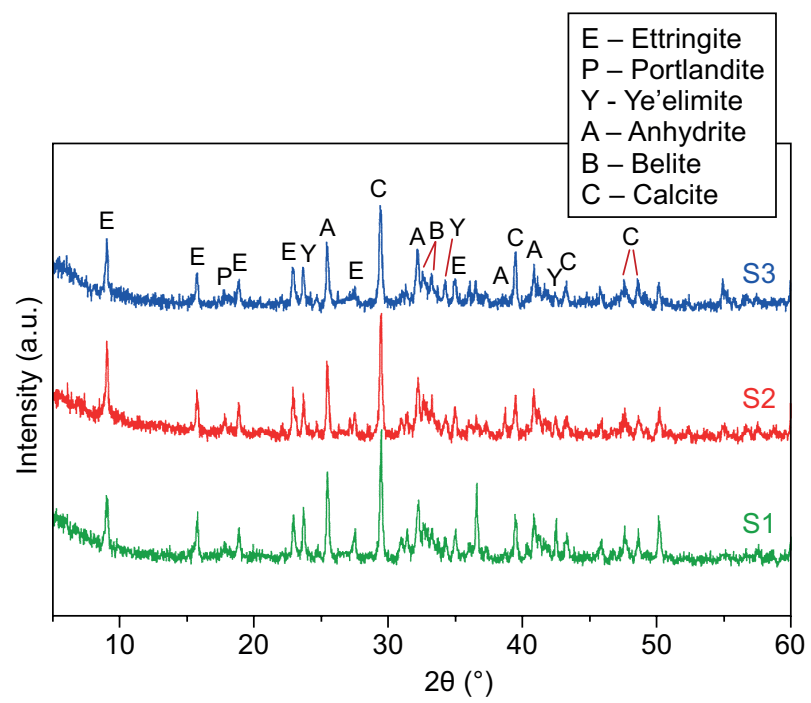

a)

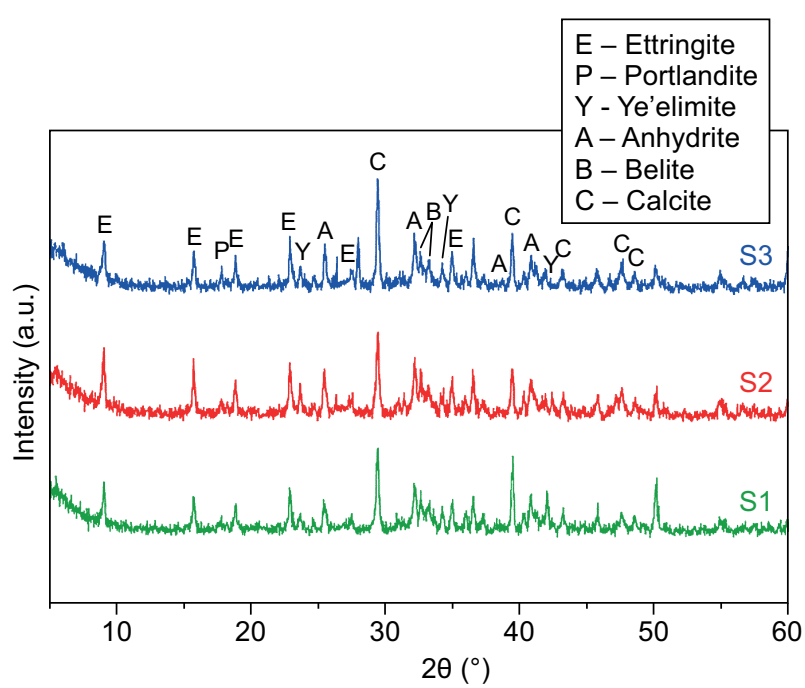

b)

Figure 7. The XRD patterns of the specimens at 4 hours (a) and 3 days (b).
In Figure 7 , the ettringite is observed as the main hydrate. At the hydration of the first several hours, the peak density of the anhydrite and ye'elimite decreases with the roughness, meanwhile the peak density of the ettringite increases. The peak density of the unhydrated minerals, such as ye'elimite, calcite, anhydrite, and belite, decreases with time. However, the peak density of the ettringite in S3 is lower than that in S1 and S2, at the age of $3 \mathrm{~d}$. This indicated that the surface roughness affects the formation of the hydration products.

\section{The effect of the interface moisture on the bond strength}

Figure 8 shows the bond strength of the different interface moistures, the bond strength of S4 remains unchanged with an increase in the hydration age. The bond strength of S3 was $3.1 \mathrm{MPa}$ and $4.5 \mathrm{MPa}$ at $4 \mathrm{~h}$ and $3 \mathrm{~d}$, respectively. This indicated that the wet substrate surface does not result in a higher bond strength than the dry substrate surface. Because the wet substrate surface provides extra water, resulting in a w/c ratio of the mortar near the combined interface and the porosity at the interface increased. This results in the reduced bond strength of the old substrate and the new materials. It can be seen from Figure 9 that the hydration product of S3 more densely distributed than S4. The presence of cracks was observed in S4 (Figure 9b), which resulted in a decrease in the bond strength. The positive effect of the reduction in the porosity caused by the drying conditions of the substrate surface may partially counteract the internal stress caused by the migration of the interface moisture so that the dry substrate surface has a higher bond strength.

In Figure 10, it can be seen that ettringite is the main hydration product. At the age of $4 \mathrm{~h}$, the peak of the ettringite in S4 is higher than that in S3, which demonstrated that the wet surface is beneficial to the formation of the hydration products. However, the ettringite peak does not obviously strengthen from $4 \mathrm{~h}$ to $3 \mathrm{~d}$.

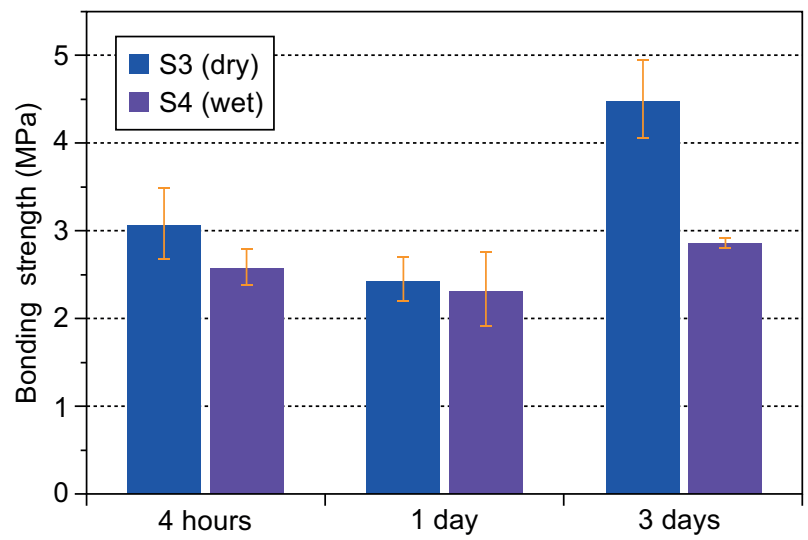

Figure 8 . The bond strength of the specimens with the different moistures. 


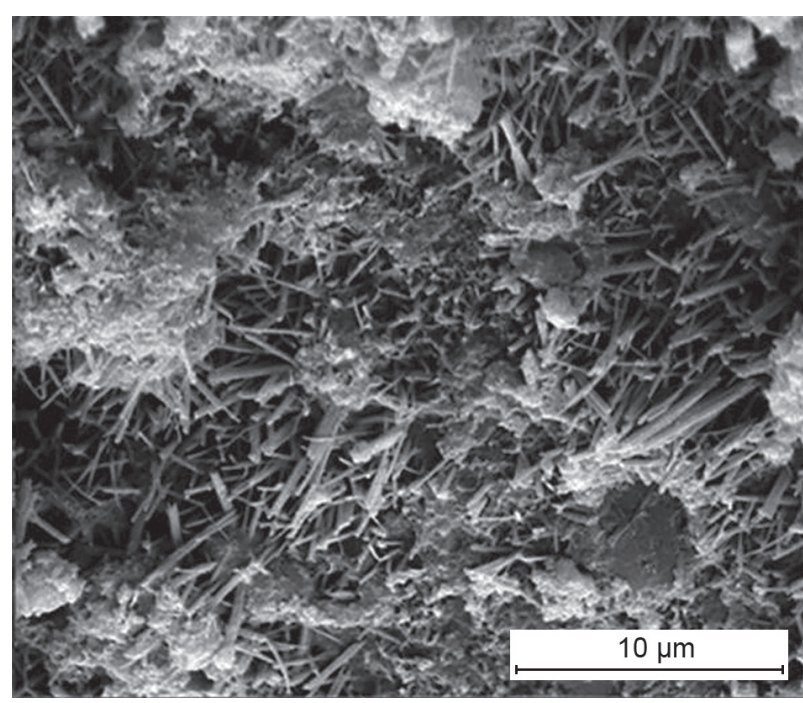

a)

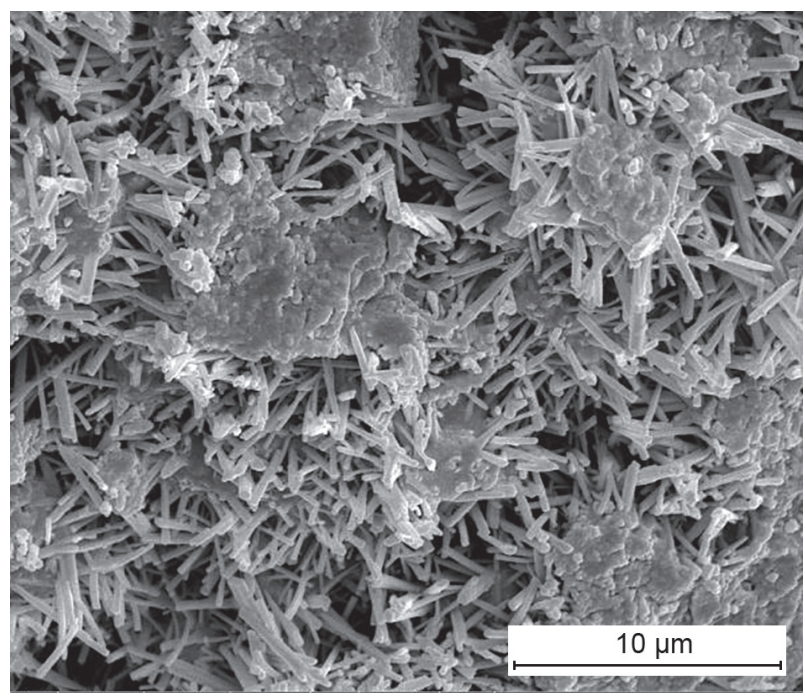

c)

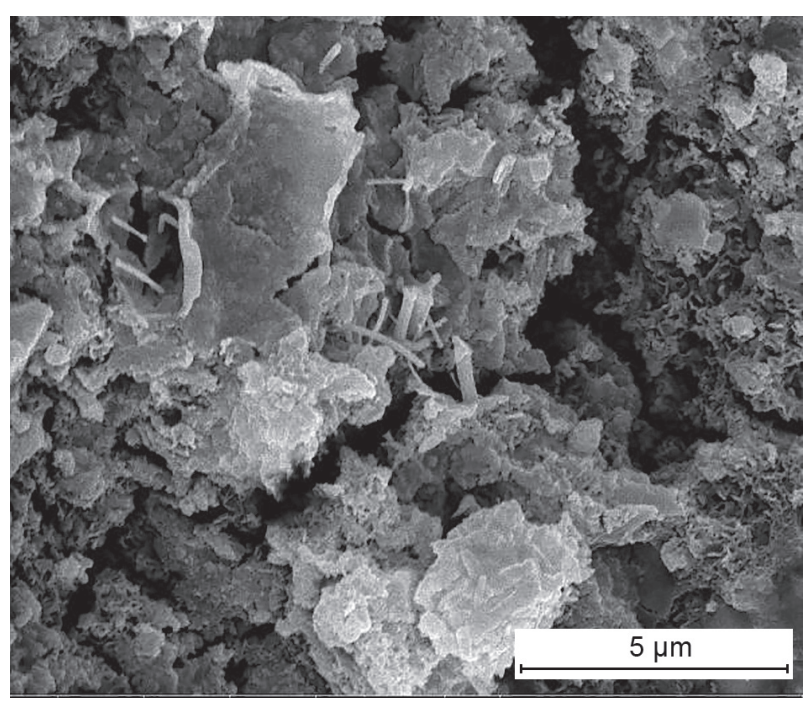

b)

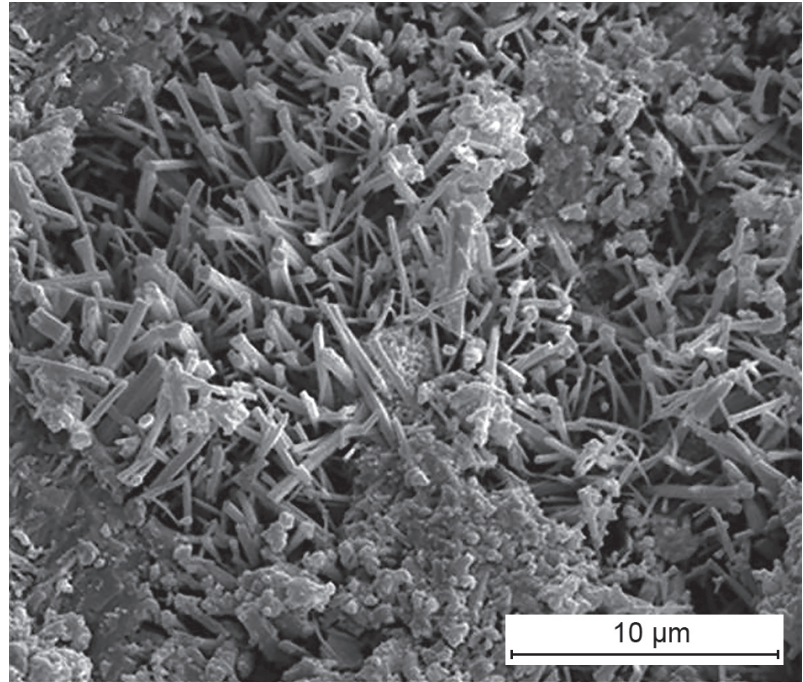

d)

Figure 9. The SEM images of the specimens: a) and b) are the SEM images of the S3 and S4 hydration for $4 \mathrm{~h}$, and c) and d) are the SEM images of the S3 and S4 hydration for $3 \mathrm{~d}$.

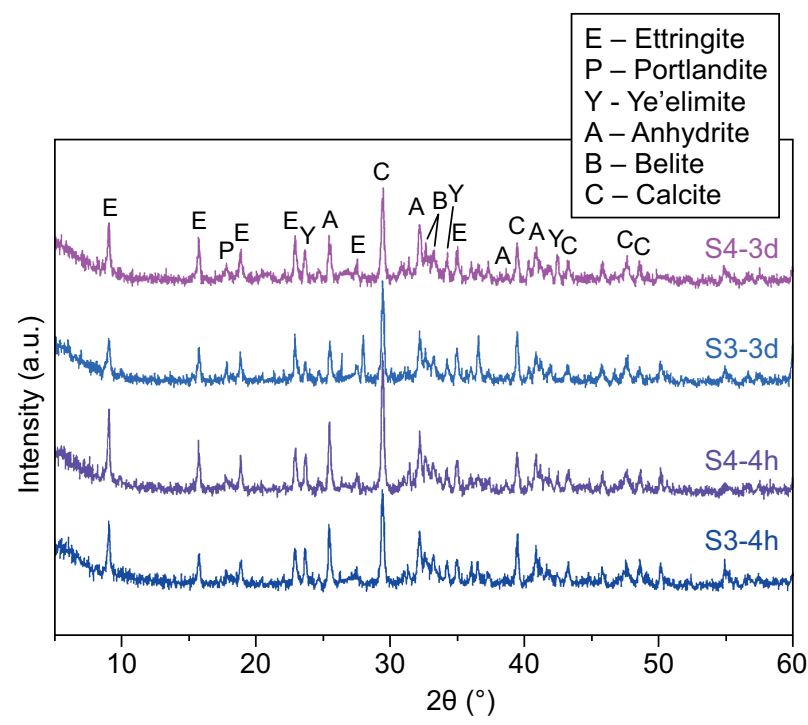

Figure 10. The XRD patterns of the specimens.
The effect of the polycarboxylate

superplasticiser on the bond strength

The results of the bond strength test of the polycarboxylate superplasticiser dosage from $0 \%$ to $1.1 \mathrm{wt}$. $\%$ is shown in Figure 11. The results show that adding an appropriate amount of the polycarboxylate superplasticiser into the CSA mortar is beneficial in improving the bond strength, and if its dosage is too high or too low, it would decrease the bond strength. When the polycarboxylate superplasticiser dosage is $0.9 \mathrm{wt} . \%$, the bond strength is the highest, and the bond strength of $4 \mathrm{~h}, 1 \mathrm{~d}$, and $3 \mathrm{~d}$ are $3.5 \mathrm{MPa}, 4.8 \mathrm{MPa}$, and 5.0 $\mathrm{MPa}$, respectively.

The polycarboxylate superplasticiser has different effects on the hydration reaction rate of the cement according to the different hydration age of the cement. After the addition of the polycarboxylate superplasticiser, 
the crystallisation process becomes slow, which is favourable for crystal growth. This results in the crystal network structure becoming denser, which can improve the strength and compactness of the cement. In addition, superplasticisers generally improve the flowability of the fresh mortar. This ability can help the fresh mortar to easily fill the scratched surface and enter the open pores of old substrate. Once the substrate is covered by the fresh mortar, the adhesion can be improved. Therefore, an appropriate amount of polycarboxylate superplasticiser is beneficial in improving the bond strength. It can be seen from Figure 12 that the specimen having a polycarboxylate superplasticiser dosage of $0.9 \mathrm{wt} . \%$ has a higher gel content and a uniform distribution of the hydration products, so it is bond strength is the highest.

\section{CONCLUSIONS}

Based on the experimental results obtained in this study, the following conclusions are drawn:

- The treatment of the substrate surface can affect the bond properties. Compared with the smooth substrate surface, the rough substrate surface is beneficial in improving the bond strength. As the interface rough-

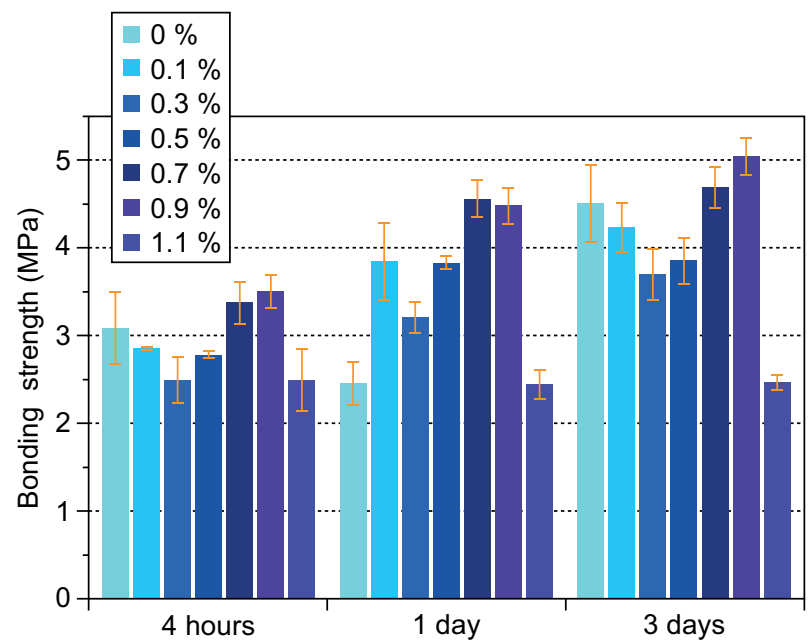

Figure 11. The bond strength of the specimens containing different polycarboxylate superplasticisers. ness increases, the bond strength at $4 \mathrm{~h}$ increases from 1.0 $\mathrm{MPa}$ to 3.1 MPa. The results indicate that the bond strength of the specimens increases with the increasing interface roughness.

- The bond strength of the dry substrate is $3.1 \mathrm{MPa}$ and $4.5 \mathrm{MPa}$ at $4 \mathrm{~h}$ and $3 \mathrm{~d}$, respectively. In contrast, the bond strength of the wet substrate is $2.6 \mathrm{MPa}$ and $2.9 \mathrm{MPa}$ at $4 \mathrm{~h}$ and $3 \mathrm{~d}$, respectively. Because the extra water present on the substrate surface would lead to the increased porosity and decreased bond strength, thus, the dry substrate surface has the highest bond strength.

- Adding an appropriate amount of a polycarboxylate superplasticiser into the CSA mortar is beneficial in improving the bond strength, and if its dosage is too high or too low, it would decrease the bond strength. When the polycarboxylate superplasticiser dosage is 0.9 wt. $\%$, the bond strength is the highest, and the bond strength of $4 \mathrm{~h}, 1 \mathrm{~d}$, and $3 \mathrm{~d}$ are $3.5 \mathrm{MPa}, 4.8 \mathrm{MPa}$, and 5.0 MPa, respectively.

\section{Acknowledgements}

Support from the National Key Research and Development Programme of China (Grant No. 2016 YFB0303505), the Shandong Provincial "Double FirstClass" University Construction Project, the Taishan Scholars Programme and the 111 Project of International Corporation on Advanced Cement-based Materials (Grant No. D17001) are greatly acknowledged.

\section{REFERENCE}

1. Guo T., Xie Y., Weng X. (2018): Evaluation of the bond strength of a novel concrete for rapid patch repair of pavements. Construction and Building Materials, 186, 790-800. doi: 10.1016/j.conbuildmat.2018.08.007

2. Qian J., You C., Wang Q., Wang H., Jia X. (2014): A method for assessing bond performance of cement-based repair materials. Construction and Building Materials, 68, 307-313. doi: 10.1016/j.conbuildmat.2014.06.048

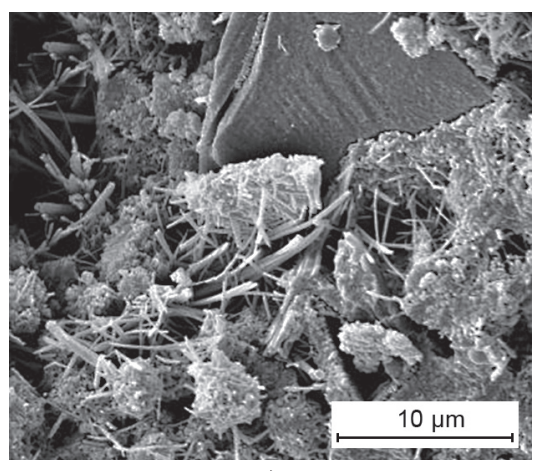

a)

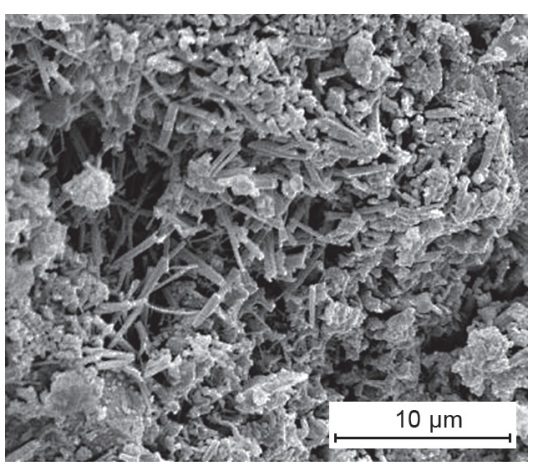

b)

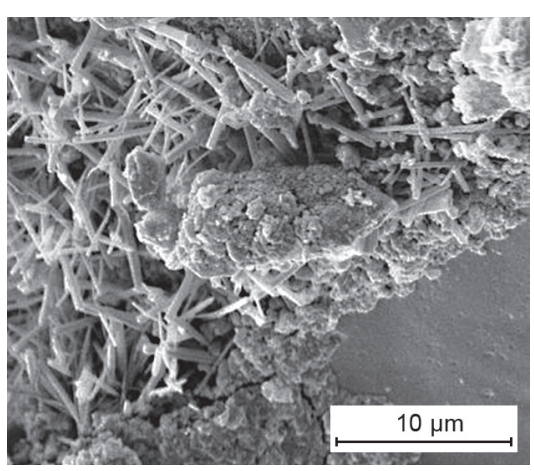

c)

Figure 12. The $3 \mathrm{~d}$ SEM images of the specimen with a $0.7 \mathrm{wt} . \%, 0.9 \mathrm{wt} . \%$ and $1.1 \mathrm{wt} . \%$ polycarboxylate superplasticiser dosage.

Ceramics - Silikáty 64 (1) 100-106 (2020) 
3. Roh I. T., Jung K. C., Chang S. H., Cho Y. H. (2015): Characterization of compliant polymer concretes for rapid repair of runways. Construction and Building Materials, 78, 77-84. doi: 10.1016/j.conbuildmat.2014.12.121

4. Alanazi H., Yang M., Zhang D., Gao Z. J. (2016): Bond strength of PCC pavement repairs using metakaolin-based geopolymer mortar. Cement and Concrete Composites, 65 , 75-82. doi: 10.1016/j.cemconcomp.2015.10.009

5. Chen Y. L., Lin C. J., Ko M. S., Lai Y. C., Chang J. E. (2011): Characterization of mortars from belite-rich clinkers produced from inorganic wastes. Cement and Concrete Composites, 33(2), 261-266. doi: 10.1016/j.cemconcomp. 2010.10.012

6. Zanotti C., Banthia N., Plizzari G. (2014): A study of some factors affecting bond in cementitious fiber reinforced repairs. Cement and Concrete Research, 63, 117-126. doi: 10.1016/j.cemconres.2014.05.008

7. He Y., Zhang X., Hooton R. D., Zhang X. (2017): Effects of interface roughness and interface adhesion on new-to-old concrete bonding. Construction and Building Materials, 151, 582-590. doi: 10.1016/j.conbuildmat.2017.05.049

8. Tayeh B. A., Bakar B. A., Johari M. M., Voo Y. L. (2013): Evaluation of bond strength between normal concrete substrate and ultra high performance fiber concrete as a repair material. Procedia Engineering, 54, 554-563. doi: 10.1016/ j.proeng.2013.03.050

9. Gadri K., Guettala A. (2017): Evaluation of bond strength between sand concrete as new repair material and ordinary concrete substrate (The surface roughness effect). Construction and Building Materials, 157, 1133-1144. doi: 10.1016/j.conbuildmat.2017.09.183

10. Courard L., Piotrowski T., Garbacz A. (2014): Near-to-surface properties affecting bond strength in concrete repair. Cement and Concrete Composites, 46, 73-80. doi: 10.1016/ j.cemconcomp.2013.11.005

11. Sen R. (2015): Developments in the durability of FRPconcrete bond. Construction and Building Materials, 78 , 112-125. doi: 10.1016/j.conbuildmat.2014.12.106

12. Cromwell J. R., Harries K. A., Shahrooz B. M. (2011): Environmental durability of externally bonded FRP materials intended for repair of concrete structures. Construction and Building Materials, 25(5), 2528-2539. doi: 10.1016/j. conbuildmat.2010.11.096

13. Garbacz A., Górka M., Courard L. (2005): Effect of concrete surface treatment on adhesion in repair systems. Magazine of Concrete Research, 57(1), 49-60. doi: 10.1680/ macr.2005.57.1.49

14. Mirmoghtadaei R., Mohammadi M., Samani N. A., Mousavi S. (2015): The impact of surface preparation on the bond strength of repaired concrete by metakaolin containing concrete. Construction and Building Materials, 80, 76-83. doi: 10.1016/j.conbuildmat.2015.01.018

15. Momayez A., Ehsani M. R., Ramezanianpour A. A., Rajaie H. (2005): Comparison of methods for evaluating bond strength between concrete substrate and repair materials. Cement and Concrete Research, 35(4), 748-757. doi: 10.1016/j.cemconres.2004.05.027

16. De La Varga I., Munoz J. F., Bentz D. P., Spragg R. P., Stutzman P. E., Graybeal B. A. (2018): Grout-concrete interface bond performance: Effect of interface moisture on the tensile bond strength and grout microstructure. Construction and Building Materials, 170, 747-756. doi: 10.1016/j.conbuildmat.2018.03.076

17. Santos P. M. D., Júlio E. N. B. S. (2011): Factors affecting bond between new and old concrete. ACI Materials Journal, 108(4), 449-456.

18. Hong L., Gu X., Lin F. (2014) : Influence of aggregate surface roughness on mechanical properties of interface and concrete. Construction and Building Materials, 65, 338-349. doi: 10.1016/j.conbuildmat.2014.04.131

19. Mouzannar H., Bost M., Leroux M., Virely D. (2017): Experimental study of the shear strength of bonded concrete-rock interfaces: surface morphology and scale effect. Rock Mechanics and Rock Engineering, 50(10), 2601-2625. doi: 10.1007/s00603-017-1259-2

20. Beushausen H., Höhlig B., Talotti M. (2017): The influence of substrate moisture preparation on bond strength of concrete overlays and the microstructure of the OTZ. Cement and Concrete Research, 92, 84-91. doi: 10.1016/j. cemconres.2016.11.017

21. Lukovic M., Ye G. (2016): Effect of moisture exchange on interface formation in the repair system studied by X-ray absorption. Materials, 9(1), 2. doi: 10.3390/ma9010002

22. Julio E. N., Branco F. A., Silva V. D. (2004): Concrete-toconcrete bond strength. Influence of the roughness of the substrate surface. Construction and Building Materials, 18(9), 675-681. doi: 10.1016/j.conbuildmat.2004.04.023

23. Omar B., Fattoum K., Maissen B., Farid B. (2010): Influence of the roughness and moisture of the substrate surface on the bond between old and new concrete. Contemporary Engineering Sciences, 3(3), 139-147.

24. Silfwerbrand J. (2003): Shear bond strength in repaired concrete structures. Materials and Structures, 36(6), 419424.doi:10.1007/BF02481068

25. Beushausen H. (2010): The influence of concrete substrate preparation on overlay bond strength. Magazine of Concrete Research, 62(11), 845-852. doi: 10.1680/macr. 2010.62.11.845 